\title{
A comparison of optic disc area measured by confocal scanning laser tomography versus Bruch's membrane opening area measured using optical coherence tomography
}

Ioana Maria Cazana* (D), Daniel Böhringer, Thomas Reinhard, Charlotte Evers, Diana Engesser, Alexandra Anton and Jan Lübke

\begin{abstract}
Background: Precise optic disc size measurements based on anatomically exact disc margins are fundamental for a correct assessment of glaucoma suspects. Computerized imaging techniques, such as confocal-scanning-lasertomography (CSLT), which applies operator defined boundaries and optical-coherence-tomography (OCT), which incorporates an alternative detectable landmark (Bruch's-membrane-opening (BMO)), have simplified the planimetry of the optic disc and BMO-area, respectively. This study's objectives are to compare both modalities for area and to define a threshold for macro-BMO using BMO-OCT.

Methods: Retrospectively, patients that simultaneously received CSLT and BMO-OCT scans were included. Their images were correlated and agreement was determined using Bland-Altman-analysis. The diagnostic power of a macro-BMO threshold using OCT was derived after creating a receiver-operating-characteristics-curve using the well-established analogous CSLT threshold $\left(2.43 \mathrm{~mm}^{2}\right)$.

Results: Our study included 373 eyes with a median optic disc area by CSLT/ BMO-area by OCT of $2.56 \mathrm{~mm}^{2}$ and $2.19 \mathrm{~mm}^{2}$ respectively. The Bland-Altman-analysis revealed a systematic deviation with a diverging tendency with increasing area, which enabled the creation of the following mathematical relation: disc-area $($ CSLT)*0.73 $+0.3=$ BMO-area (OCT). BMO-area of $2.19 \mathrm{~mm}^{2}$ showed the best diagnostic power for identifying macro-BMOs using OCT (sensitivity: 75\%, specificity: 86\%).
\end{abstract}

Conclusions: Area measurements (CSLT optic disc area vs. BMO-area by OCT) showed a systematic deviation with a divergent tendency with increasing size. Our mathematical equation offers an estimated comparison of these anatomically diverse entities. Considering BMO-OCT' anatomical accuracy, the $2.19 \mathrm{~mm}^{2}$ threshold may improve discernment between glaucoma suspects and norm variants.

Keywords: Macrodiscs, BMO-OCT, CSLT, Glaucoma

* Correspondence: ioana.maria.cazana@uniklinik-freiburg.de

Eye Center, Medical Center, Faculty of Medicine, University of Freiburg,

Killianstrasse 5, 79106 Freiburg, Germany

(c) The Author(s). 2021 Open Access This article is licensed under a Creative Commons Attribution 4.0 International License, which permits use, sharing, adaptation, distribution and reproduction in any medium or format, as long as you give appropriate credit to the original author(s) and the source, provide a link to the Creative Commons licence, and indicate if changes were made. The images or other third party material in this article are included in the article's Creative Commons licence, unless indicated otherwise in a credit line to the material. If material is not included in the article's Creative Commons licence and your intended use is not permitted by statutory regulation or exceeds the permitted use, you will need to obtain permission directly from the copyright holder. To view a copy of this licence, visit http://creativecommons.org/licenses/by/4.0/. The Creative Commons Public Domain Dedication waiver (http://creativecommons.org/publicdomain/zero/1.0/) applies to the data made available in this article, unless otherwise stated in a credit line to the data. 


\section{Background}

Primary open angle glaucoma remains one of the leading causes of blindness worldwide [1]. The condition is defined as a progressive loss of the nerve fiber layer tissue (NFLT) with subsequent visual field damage [2]. It is most commonly clinically detectable as structural alterations to the optic nerve head $(\mathrm{ONH})$ [3]. However, even healthy $\mathrm{ONHs}$ display remarkable morphological variations. Additionally, the assessment of the $\mathrm{ONH}$ varies greatly depending on examination technique, thus adding to the complexity of the correct diagnosis of glaucoma for even the most experienced physicians $[4,5]$.

The accurate identification of the optic disc margin, the outer delineation of the NFLT, and the exact calculation of the optic disc size are two key components for all quantitative assessments of the $\mathrm{ONH}$. Nevertheless, great disagreement exists regarding the exact definition of the $\mathrm{ONH}$ margin, which in turn can greatly affect the ONH size. While some consider the ring of Elschnig, a dense connective tissue rising up from the anterior segment of the sclera to join Bruch's membrane and thereby enclosing the choroid, to be the real margin of the ONH [6-8], others regard Bruch's membrane opening (BMO), which can sometimes extend beyond the border tissue, to be the clinically visible margin as shown in monkeys [9-11]. This increases the complexity of the precise calculation of ONH size. Several measuring techniques (histomorphometry, slit-lamp biomicroscopy, planimetry based on stereophotographs, and computerized imaging), with differing strengths and limitations, have to date been employed. Nevertheless, imaging methods such as confocal-scanning-laser-tomography (CSLT), which applies operator defined boundaries based on the ring of Elsching and optical-coherencetomography (OCT), which incorporates an alternative detectable landmark (BMO), have automated segmentation and have simplified the planimetry of the area. Moreover, an assessment based on an identifiable landmark, such as the BMO by OCT, could significantly improve clinical evaluations of ambiguous cases. To date, these two modalities have not been directly correlated. Therefore, it is the purpose of our study to put the two imaging modalities (CSLT and BMO-OCT) in direct comparison for area.

Optic disc areas above $2.43 \mathrm{~mm}^{2}$ are considered enlarged in CSLT, yet no parallel threshold exists for areas calculated using BMO as a margin by means of OCT. The differentiation between glaucomatous $\mathrm{ONHs}$ and macrodiscs, which are large ONHs with a funduscopically thinned NFLT and an enlarged cup, is clinically challenging and can therefore lead to a misdiagnosis. While Jonas et al. (1992) concluded a positive correlation between optic disc size and the NFLT [12], both the Blue Mountain and the Reykavic Eye Study showed a strong correlation between the optic disc size and the susceptibility to glaucoma $[13,14]$. These findings reinforce the importance of a prompt and robust detection of macrodiscs. While the BMO-OCT cannot directly discern between macro and non-macrodiscs, its anatomical accuracy in area calculation based on the $\mathrm{BMO}$ persuaded us to define a threshold for identifying macro-BMOs.

\section{Methods}

Data acquisition in this single-center retrospective study was performed at the Eye Center, University Hospital Freiburg. The study received approval from the University of Freiburg ethics committee (vote no. 288/19) and followed all tenants of the Declaration of Helsinki. Data acquisition was based on our electronic patient management system. Patients receiving both CSLT and OCT scans without a glaucoma diagnosis from 2014 until the end of 2018 on the same examination day were identified and included in the analysis. CSLT and OCT scans were performed using the Heidelberg Engineering Retina Tomograph III (HRT II/3. ONH Acquisition Module 3.0.7.0; Heidelberg Engineering GmbH, Heidelberg, Germany) and the Spectralis OCT (HRT ONH Viewing Module 3.2.0.0; Heidelberg Engineering GmbH, Heidelberg, Germany). Standard operating procedures were followed. All assessments were carried out by experienced medical technicians.

In CSLT, disc margins were segmented manually by our operators (two in total) and reviewed by a glaucoma expert (three in total). In cases where disc margins showed significant error, images were reassessed by the glaucoma specialist and margins were adjusted. The area was automatically computed using the internal software of the device.

OCT imaging was also carried out by the same medical technicians with the aforementioned commercially available device. Both centration of the scan to the optic disc as well as possible errors in BMO detection were corrected by the same glaucoma specialists. The area within BMO was calculated using the built in software.

Statistical analysis was then performed using R statistical software [15]. A systematic deviation between the two imaging methods was then assessed through a Bland-Altman-plot. On this basis, we created a correlation formula between both methods using linear regression.

Lastly, using the CSLT threshold for macrodiscs $\left(2.43 \mathrm{~mm}^{2}\right)$ as a benchmark, we created a receiver operating characteristics-curve (ROC) for the diagnostic power of BMO area as computed through OCT. On this basis we suggested an analogous threshold to detect macro-BMOs using OCT. 
Table 1 Patients characteristics

\begin{tabular}{ll}
\hline Number of eyes & $\mathbf{3 7 3}$ \\
\hline Mean age & 52.58 years \\
Glaucoma status & \\
Diagnosed glaucoma & $27.57 \%$ \\
Glaucoma suspects & $43.24 \%$ \\
Healthy & $29.19 \%$ \\
Refractive error (spherical equivalent) & $-0.63 \mathrm{D}(1$ st quartile $-2.88 \mathrm{D}$, \\
Visual field mean deviation & $3 \mathrm{rd}$ quartile $0.50 \mathrm{D})$ \\
& $0.4 \mathrm{~dB}(1 \mathrm{st}$ quartile $-0.90 \mathrm{~dB}$, \\
\hline
\end{tabular}

\section{Results}

373 eyes, with an average age of 52.58 years, were included in our study. Of these, $27.57 \%$ had glaucoma, $43.24 \%$ remained suspects, and $29.19 \%$ showed no signs of the condition. The median visual field mean deviation recorded was $0.4 \mathrm{~dB}$ (1st quartile $-0.90 \mathrm{~dB}$, 3rd quartile $2.30 \mathrm{~dB}$ ). The refractive error was available for 322 eyes and showed a median spherical equivalent of $-0.63 \mathrm{D}$ (1st quartile - 2.88 D, 3rd quartile 0.50 D). Table 1 summarizes the aforementioned patient characteristics. The median optic disc area using CSLT was $2.56 \mathrm{~mm}^{2}$ (1st quartile 2.19, 3rd quartile 2.95) and the median BMOarea using OCT was $2.19 \mathrm{~mm}^{2}$ (1st quartile 1.89, 3rd quartile 2.52). Figure 1 shows a glaucoma suspect's scans (BMO-OCT 1a and CSLT 1b). The bivariate correlation analysis between the two measurements is shown in Fig. 2. We employed the plot and extrapolated a relation, which was used to create the following equation between the two imaging modalities: Disc Area (CSLT) * $0.73+$ 0.3 = BMO-area (OCT).

A systematic deviation between the two imaging techniques was noted with a divergent tendency with increasing area as shown in the Bland-Altmananalysis (Fig. 3). The ROC-curve (Fig. 4) showed that a BMO-area of $2.19 \mathrm{~mm}^{2}$ or greater in OCT with a $75 \%$ sensitivity and $86 \%$ specificity had the greatest diagnostic power to discriminate macro-BMOs from norm variants. The area under the curve (AOC) was 0.88 .
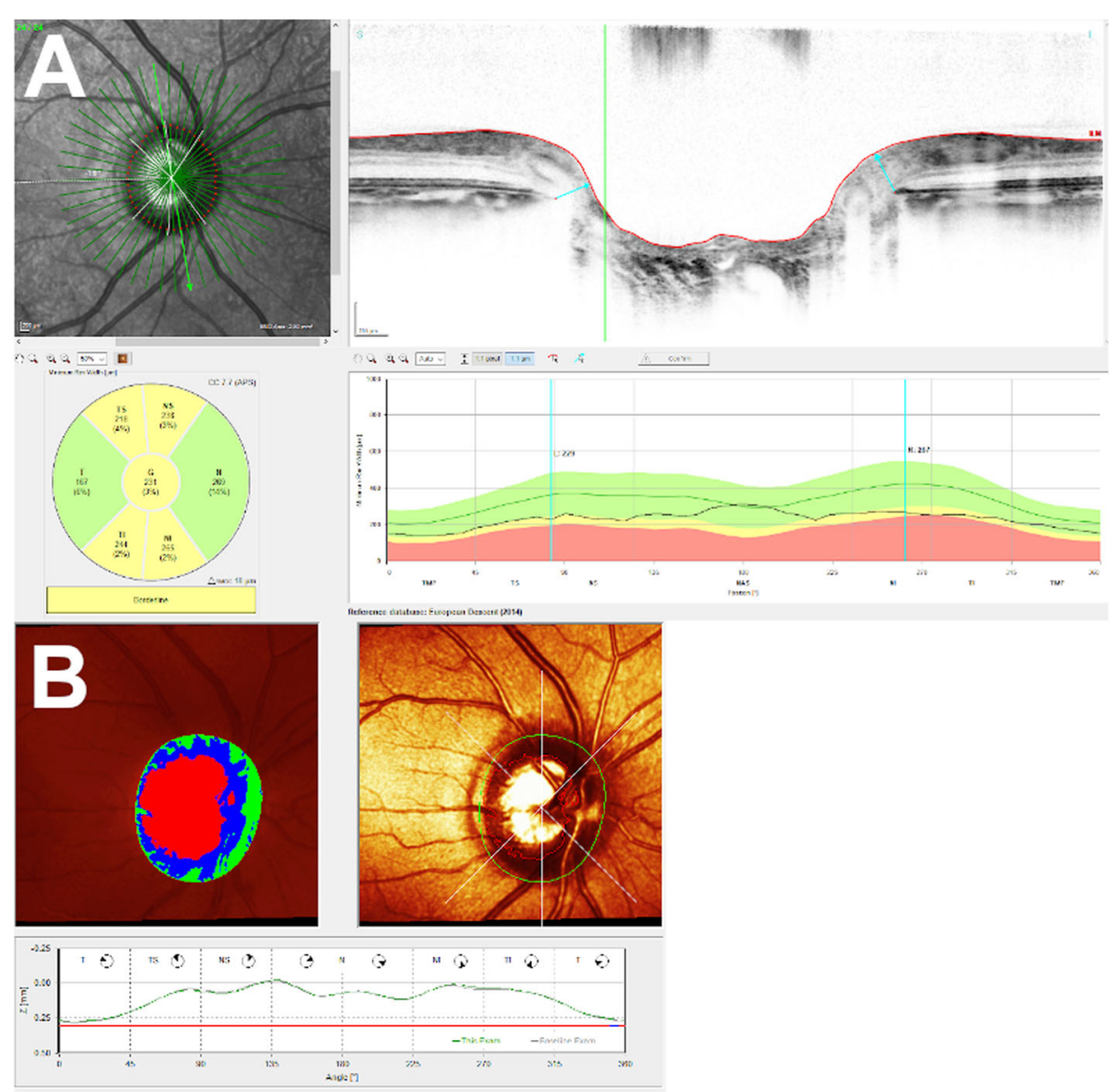

Fig. 1 a OCT defined BMO- area from a glaucoma suspect's right eye. b CSLT defined optic disc area from the same glaucoma suspect's right eye 


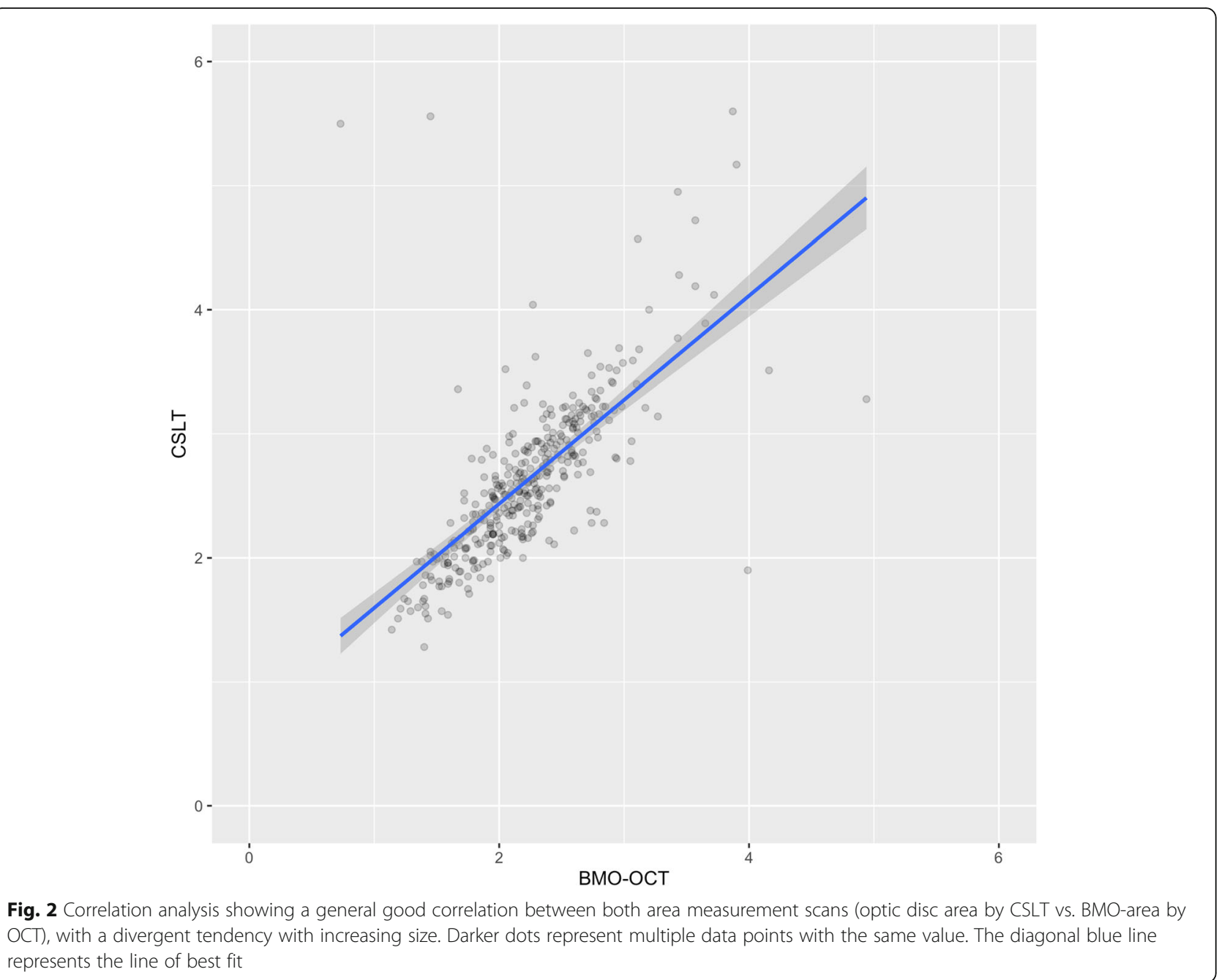

\section{Discussion}

Our study presents the first comparison between disc area measurements by CSLT versus BMO-area by OCT. We demonstrate a tight correlation between both measuring techniques that weakens slightly with increasing size. On this basis, we suggest a threshold for macroBMOs using the BMO-area as calculated by OCT (2.19 $\mathrm{mm}^{2}$ ) that parallels the well-established CSLT benchmark $\left(2.43 \mathrm{~mm}^{2}\right)$.

It is worth noting that a significant number of our examined ONHs present enlarged discs. At our hospital, patients suspicious of marcodiscs routinely receive both CSLT and BMO-OCT scans. Consequently, this may impact the statistical outcome. Nevertheless, considering the obtained median values for CSLT $\left(2.56 \mathrm{~mm}^{2}\right)$ and BMO-OCT $\left(2.19 \mathrm{~mm}^{2}\right)$, one notices that mostly borderline ONHs (slightly below or above the macrodisc threshold) were included in our analysis, thus showing clinical relevance.

The optic disc margin is a fundamental landmark as it denotes the outer-most boundary of NFLT of the ONH.
Its precise identification is crucial for the correct quantitative assessment of the NFLT. Historically, the ring of Elschnig has accounted for the funduscopically perceived whitish halo representing the $\mathrm{ONH}$ margin [8]. This long standing paradigm has been widely challenged following the advent of the OCT, which allows for a 3D insight into the ONH boundary anatomy. Suppot for this theory can be found in a study performed on 28 monkeys which showed that the BMO constituted the disc margin in the majority of eyes [11]. These findings are highly relevant for an accurate interpretation of disc area data. Multiple studies have been performed comparing various disc size measuring techniques. The manual outlining of the $\mathrm{ONH}$ boundary based on the perceived ring of Elschnig as required in both stereoscopic photography and CSLT can be highly subjective. Jonas et al. (1998) obtained larger neuroretinal rim area results through CSLT than with disc photography [16]. This was attributed in part to the manual outlining of the margin, which can be better detected in disc photographs versus disc scans [16].On the contrary, OCT tended to measure 


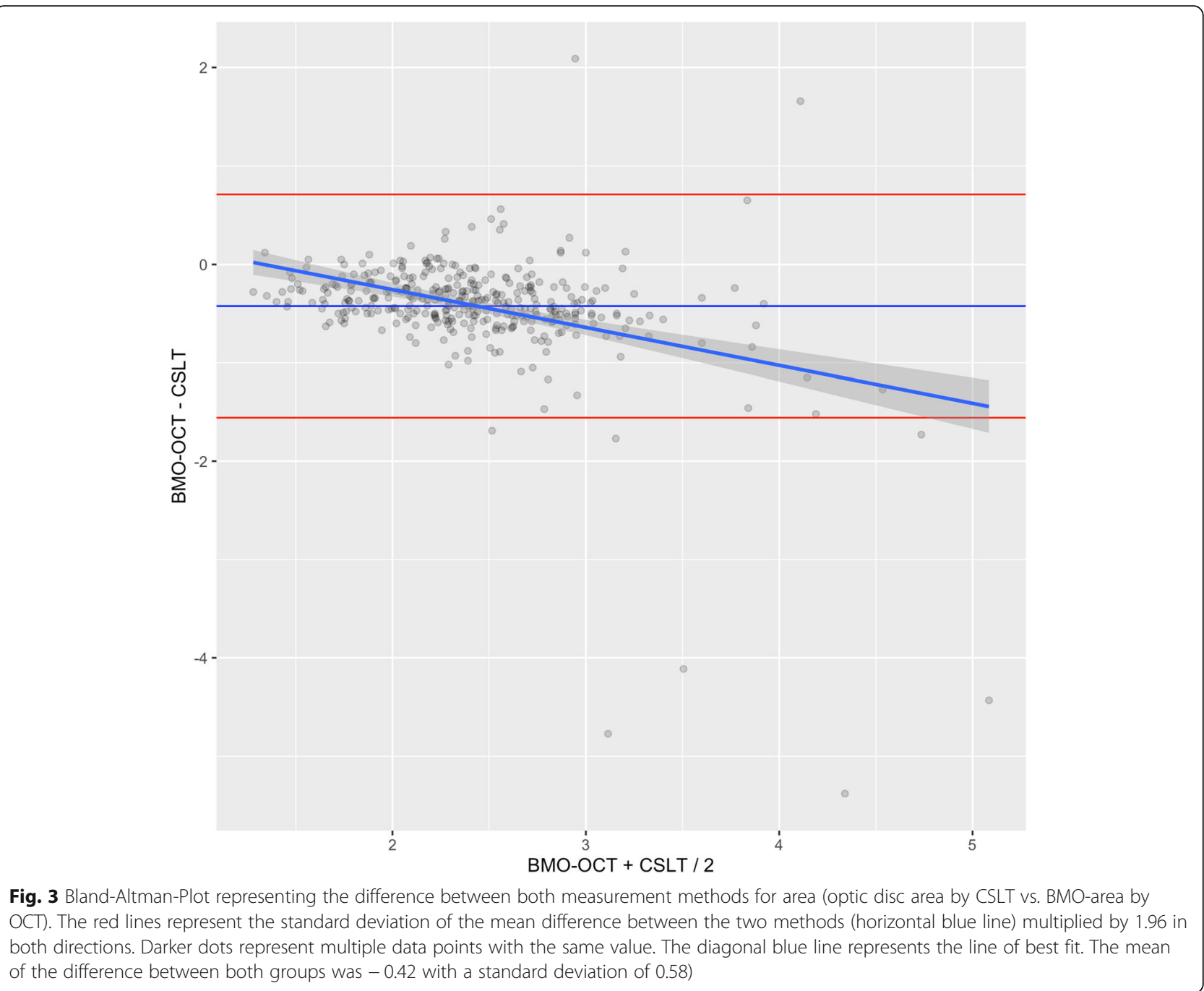

optic disc size about 10\% smaller when compared to disc photographs [17]. Yapp et al. (2018) compared operatordriven (stereoscopic photography and CSLT) and automatic (BMO-OCT) disc size area measuring techniques [18]. The results showed that while CSLT and disc photography showed good correlation, BMO size tended to be smaller when measured by OCT. Additionally, a slightly greater deviation tendency was noted with increasing disc size. These findings are in line with our results, which showed larger disc area measurements by CSLT vs. BMO-areas by OCT, therefore reaffirming the importance of an objective and anatomically precise margin identification process. Our proposed correlation formula may thus provide physicians an anatomically more accurate estimation of the $\mathrm{ONH}$ area in centers where only a CSLT is available.

Not only disc margins but also optical magnification can significantly alter disc area results. Littmann (1982) introduced a new formula to determine the true size of the optic disc while taking into consideration both camera and eye magnification [19]. One study looking at highly myopic discs showed better agreement between CSLT and stratus OCT when the OCT results were corrected using the modified axial length method derived from Bennet et al. (1994) [20, 21]. Similarly, Luebke et al. (2017) concluded a mean change of $7.71 \%$ in BMO for every $0.3 \mathrm{~mm}^{2}$ change in corneal compensation, thus again showing the significance of ocular magnification properties [22]. Our present study did not account for either axial length or corneal refractive errors. Nevertheless, even if corneal compensation could have potentially increased our mean optic disc size the effect should be about the same for both measuring methods.

BMO-based parameters have been analyzed for a number of aberrant disc configurations. The BMO-minimum rim width (MRW) has proven to be superior to other glaucoma detection methods for macrodiscs [23]. In spite of this, CSLT remains a widespread tool even though it has been signaled that the diagnostic value of the Moorfields-Regression-analysis and the Glaucoma 


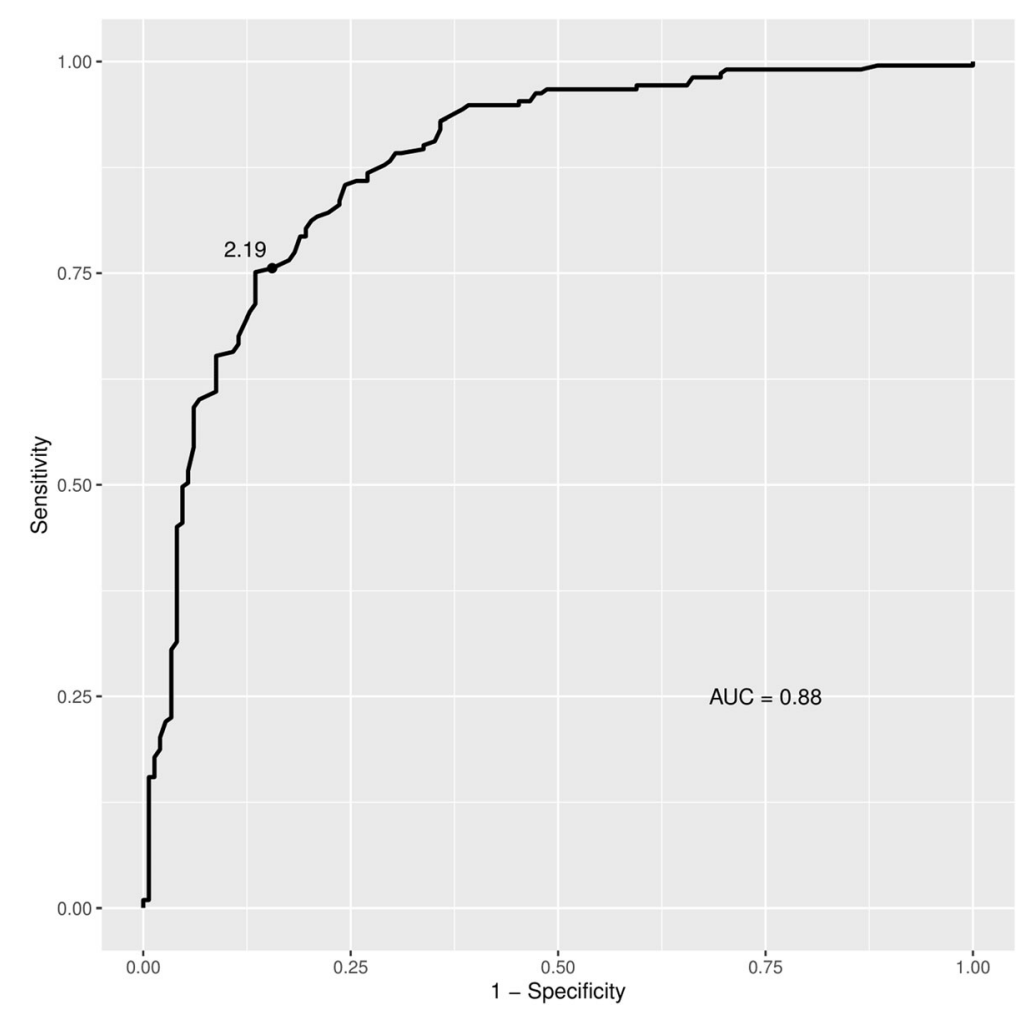

Fig. 4 Receiver-operating-characteristics analysis. Discrimination of macro-BMO by OCT

Probability Score decreases when analyzing ONHs with extreme sizes. This results in an increase of false positive glaucoma diagnosis for macrodiscs [24]. Since macrodiscs have a misleading appearance which can often lead to a misdiagnosis of glaucoma, the correct identification and assessment of this entity via instrument based diagnostic becomes vital. When looking at macrodiscs (disc area $>2.43 \mathrm{~mm}^{2}$ in CSLT), one study obtained larger mean disc areas in glaucomatous, non-glaucomatous and ocular hypertension patients through BMO-OCT versus CSLT [23]. This may in part be due to the systematic deviation between the two imaging techniques with increasing disc area we have observed. Additionally, macrodiscs tend to be underexposed because of the intense reflection of the large cup area when brightness control is left in the automatic mode in CSLT, therefore complicating defining the exact margin [25]. This argument reinforces the relevance of an automatic and accurate identification of the BMO-margin as enabled by OCT.

OCT has become readily available to many physicians and the BMO-analysis is shown to have a superior diagnostic power to all other parameters for macrodiscs [23]. These factors along with the argument that glaucoma susceptibility increases with increasing disc size require physicians to correctly identify patients. Our proposed threshold for macro-BMO, computed by means of OCT $\left(2.19 \mathrm{~mm}^{2}\right)$, simplifies and automates the detection process of discs at risk.

\section{Conclusions}

Computerized imaging techniques have significantly enhanced the glaucoma detection process and consequently the evaluation of its progression. With its threedimensional insight into the $\mathrm{ONH}$ structures and its objectivity, the BMO-OCT allows for a precise quantitative assessment of the NFLT for a variety of aberrant ONHs. Therefore, our proposed threshold for macro-BMOs as computed through OCT $\left(2.19 \mathrm{~mm}^{2}\right)$, with a $75 \%$ sensitivity and an $86 \%$ specificity, simplifies and automates the detection process and enables an anatomically correct identification of macro-BMO. Our data comparing optic disc area measurements by CSLT to BMO-area measurements by OCT show a good correlation with a systematic deviation and a divergent tendency with increasing disc size. This reinforces the importance of an accurate insight into border anatomy for aberrant discs, such as the macrodiscs, in order to correctly discern between glaucoma suspects and norm variants.

\section{Abbreviations}

BMO: Bruch's membrane opening; OCT: Optical coherence tomography; BMO-OCT: Bruch's membrane opening optical coherence tomography; 
CSLT: Confocal scanning laser tomography; ONH: Optic nerve head NFLT: Nerve fiber layer tissue

\section{Acknowledgements}

Not applicable.

\section{Authors' contributions}

IMC and $J$ designed the study and performed data acquisition. IMC, JL and DB performed statistical analysis. TR and AA helped with data interpretations. IMC and JL drafted the manuscript. CE and DE helped with proofreading and editing. All authors read and approved the final manuscript.

\section{Funding}

The study received no external funding. Open Access funding enabled and organized by Projekt DEAL.

\section{Availability of data and materials}

The datasets used and/or analyzed during the current study are available from the corresponding author on reasonable request.

\section{Compliance with Ethical Standards}

\section{Ethics approval and consent to participate}

The local ethics committee of the University of Freiburg approved this retrospective observational study (vote no. 288/19). Considering the retrospective nature of the study, no written consent to storing or analyzing data was necessary.

\section{Animal testing}

Not applicable

\section{Consent for publication}

Not applicable.

\section{Competing interests}

The authors declare that they have no competing interests.

Received: 9 June 2020 Accepted: 29 December 2020

Published online: 12 January 2021

\section{References}

1. Weinreb RN, Khaw PT. Primary open-angle glaucoma. The Lancet. 2004;363: 1711-20.

2. Sommer A, Pollack I, Maumenee AE. Optic disc parameters and onset of glaucomatous field loss. I. Methods and progressive changes in disc morphology. Arch Ophthalmol Chic III 1960. 1979;97:1444-8.

3. Sommer A, Katz J, Quigley HA, Miller NR, Robin AL, Richter RC, et al. Clinically detectable nerve fiber atrophy precedes the onset of glaucomatous field loss. Arch Ophthalmol Chic III 1960. 1991;109:77-83.

4. Reis ASC, O'Leary N, Yang H, Sharpe GP, Nicolela MT, Burgoyne CF, et al. Influence of Clinically Invisible, but Optical Coherence Tomography Detected, Optic Disc Margin Anatomy on Neuroretinal Rim Evaluation. Invest Ophthalmol Vis Sci. 2012;53:1852-60.

5. Reis ASC, Sharpe GP, Yang H, Nicolela MT, Burgoyne CF, Chauhan BC. Optic Disc Margin Anatomy in Glaucoma Patients and Normal Controls with Spectral Domain Optical Coherence Tomography. Ophthalmology. 2012;119: 738-47

6. Fantes FE, Anderson DR. Clinical histologic correlation of human peripapillary anatomy. Ophthalmology. 1989;96:20-5.

7. Anderson DR, Hoyt WF. Ultrastructure of intraorbital portion of human and monkey optic nerve. Arch Ophthalmol Chic III 1960. 1969;82:506-30.

8. Jonas J, Airaksinen P, Robert Y. Definitionsentwurf der intra- und parapapillären Parameter für die Biomorphometrie des Nervus opticus. Klin Monatsblätter Augenheilkd. 1988;192:621.

9. Downs JC, Yang H, Girkin C, Sakata L, Bellezza A, Thompson H, et al. Threedimensional histomorphometry of the normal and early glaucomatous monkey optic nerve head: neural canal and subarachnoid space architecture. Invest Ophthalmol Vis Sci. 2007;48:3195-208.

10. Strouthidis N, Yang H, Reynaud J, Grimm J, Gardiner S, Fortune B, et al. Comparison of Clinical and Spectral Domain Optical Coherence
Tomography Optic Disc Margin Anatomy. Invest Ophthalmol Vis Sci. 2009; 50:4709-18.

11. Strouthidis NG, Yang H, Downs JC, Burgoyne CF. Comparison of Clinical and Three-Dimensional Histomorphometric Optic Disc Margin Anatomy. Invest Ophthalmol Vis Sci. 2009;50:2165-74.

12. Jonas JB, Schmidt AM, Müller-Bergh JA, Schlötzer-Schrehardt UM, Naumann GO. Human optic nerve fiber count and optic disc size. Invest Ophthalmol Vis Sci. 1992;33:2012-8.

13. Wang L, Damji KF, Munger R, Jonasson F, Arnarsson A, Sasaki H, et al. Increased disk size in glaucomatous eyes vs normal eyes in the Reykjavik eye study. Am J Ophthalmol. 2003;135:226-8.

14. Healey PR, Mitchell P. Optic disk size in open-angle glaucoma: the Blue Mountains Eye Study. Am J Ophthalmol. 1999;128:515-7.

15. R Core Team. R: A Language and Environment for Statistical Computing. 2019. https://www.R-project.org.

16. Jonas J, Mardin C, Grundler A. Comparison of measurements of neuroretinal rim area between confocal laser scanning tomography and planimetry of photographs. Br J Ophthalmol. 1998;82:362-6.

17. Samarawickrama C, Pai A, Huynh SC, Burlutsky G, Jonas JB, Mitchell P. Measurement of optic nerve head parameters: comparison of optical coherence tomography with digital planimetry. J Glaucoma. 2009;18:571-5.

18. Yapp M, Rennie G, Hennessy MP, Kalloniatis M, Zangerl B. The impact of optic nerve and related characteristics on disc area measurements derived from different imaging techniques. PloS One. 2018;13:e0190273.

19. Littmann $\mathrm{H}$. [Determination of the real size of an object on the fundus of the living eye]. Klin Monatsbl Augenheilkd. 1982;180:286-9.

20. Bennett AG, Rudnicka AR, Edgar DF. Improvements on Littmann's method of determining the size of retinal features by fundus photography. Graefes Arch Clin Exp Ophthalmol Albrecht Von Graefes Arch Klin Exp Ophthalmol. 1994;232:361-7.

21. Leung CK, Cheng ACK, Chong KKL, Leung KS, Mohamed S, Lau CSL, et al. Optic Disc Measurements in Myopia with Optical Coherence Tomography and Confocal Scanning Laser Ophthalmoscopy. Invest Ophthalmol Vis Sci. 2007:48:3178-83.

22. Luebke J, Böhringer D, Reinhard T, Anton A. [Bruch's Membrane Opening in OCT in Correlation with Corneal Correction - a Pilot Study]. Klin Monatsbl Augenheilkd. 2017:234:918-23.

23. Enders P, Schaub F, Adler W, Hermann MM, Dietlein TS, Cursiefen C, et al. Bruch's membrane opening-based optical coherence tomography of the optic nerve head: a useful diagnostic tool to detect glaucoma in macrodiscs. Eye Lond Engl. 2018;32:314-23.

24. Plange N, Hirsch T, Bienert M, Remky A. Spezifität der konfokalen Scanning Laser Ophthalmoskopie bei großen Sehnerven mit physiologischer Exkavation. Klin Monatsblätter Für Augenheilkd. 2014:231:164-9.

25. Dascalu A, Alexandrescu C, Pascu R, llinca R, Popescu V, Ciuluvica R, et al. Heidelberg Retina Tomography Analysis in Optic Disks with Anatomic Particularities. J Med Life. 2010;3:359-64.

\section{Publisher's Note}

Springer Nature remains neutral with regard to jurisdictional claims in published maps and institutional affiliations.
Ready to submit your research? Choose BMC and benefit from:

- fast, convenient online submission

- thorough peer review by experienced researchers in your field

- rapid publication on acceptance

- support for research data, including large and complex data types

- gold Open Access which fosters wider collaboration and increased citations

- maximum visibility for your research: over $100 \mathrm{M}$ website views per year

At $\mathrm{BMC}$, research is always in progress.

Learn more biomedcentral.com/submissions 